neonatal convulsions, is a unique case report from Tokushima

University, Japan (Mori K, Yano I, Hashimoto T).

\title{
EPILEPSY SURGERY AND TUBEROUS SCLEROSIS
}

The results of operation for treatment of epilepsy in 5 male and 4 female patients with tuberous sclerosis (TSC) in a 5-year period from 1986-1990 are reported from the Mayo Clinic. Pathological examination of resected lesions demonstrated 7 cortical tubers and 2 astocytic hamartomas. MRIs correlated with clinical and focal EEG findings. Seven patients are free from seizures and 2 are partially controlled. In selected TSC patients with single or multiple cerebral lesions, both the primary and secondary epileptogenic lesions were modified by removal of the primary ictal focus. (Bebin EM, Kelly PJ, Gomez MR. Surgical treatment for epilepsy in cerebral tuberous sclerosis. Epilepsia July/Aug 1993; 34:651-657). (Reprints: Dr MR Gomez, Dept of Neurology, Mayo Clinic, 200 First St, SW, Rochester, MN 55905).

COMMENT. Results of surgery for epilepsy due to cortical dysplasia (CD) are reviewed in 17 patients treated at the Maudsley Hospital, London (Hirabayashi S et al. I Neurol Neurosurg Psychiatry July 1993; $\underline{56}$ :765). Only 6 became free or almost free from seizures, and 8 had no relief. Outcome related to the extent of the pathology but not to histology. Lesions outside the temporal and frontal lobes and generalized interictal EEG abnormalities, reflecting extensive or multiple lesions, correlated with poor surgical outcome. MRI was abnormal in 5 of 7 patients examined, contrasting with a low detection rate of abnormalities by CT scan. The use of MRI and PET should improve the identification of CD patients amenable to surgery.

\section{SEIZURES AND NEUROFIBROMATOSIS I}

Twenty-two (6\%) patients, ages 5 to 57 years, had developed seizures among 359 attending a neurofibromatosis clinic at the Dept of Neurology, Children's Hospital, Harvard Med School, Boston. The majority of seizures could be attributed to causes unrelated to NF1: 6 had febrile seizures and 3 had primary generalized epilepsy with onset before 5 years. Complex partial seizures in $9(41 \%)$, infantile spasms in 1, and seizures with aqueductal stenosis in 2 may have been caused by NF1, but no specific brain lesions were detected. None of the seizures was a symptom of brain tumor, and neuroimaging failed to uncover a seizure focus. Routine EEG of all patients with NF1 was considered unproductive. (Korf BR, Carrazana E, Holmes GL. Patterns of seizures observed in association with neurofibromatosis 1. Epilepsia July/Aug 1993;34:616-620). (Reprints: Dr BR Korf, Children's Hospital, 300 Longwood Ave, Boston, MA 02115). 
COMMENT. Seizures appear to be relatively uncommon in association with NF1. A possible increased frequency of infantile spasms in NF1 patients was suggested in two previous reports (Huson SM et al. Brain 1988;111:1355; see Millichap JG, Ed. Progress in Pediatric Neurology, Chicago, PNB, 1991).

\section{$\underline{\text { ANTIEPILEPTIC DRUGS }}$}

\section{USE OF AED LEVELS BY PEDIATRIC NEUROLOGISTS}

Replies from 56 of 60 pediatric neurologists surveyed regarding the use and value of antiepileptic drug (AED) levels were evaluated in the Departments of Pediatrics and Toxicology, Dalhousie University and The IWK Children's Hospital, Halifax, Canada. The majority of respondents were in academic practice. Drug concentrations were measured frequently or always at the following times: 1) pre-dose (trough) by $63 \%, 2$ ) at the expected peak by $18 \%$, 3 ) at time of clinic visit by $60 \%, 4$ ) at each office visit by $38 \%, 5$ ) when a second AED was introduced by $77 \%, 6$ ) on high doses by $96 \%, 7)$ for possible toxicity by $96 \%, 8$ ) when compliance in doubt by $95 \%, 9)$ routinely once or twice a year by $60 \%$, and 10 ) more than twice a year by $18 \%$ of respondents. AED monitoring was generally perceived as valuable and results frequently (75\%) influenced clinical decisions. Therapeutic ranges in laboratories varied; they were most consistent for phenytoin $(10-20 \mathrm{mcg} / \mathrm{ml})$ and most variable for carbamazepine, with lower limits from $3-9$ and upper limits from $8-12 \mathrm{mcg} / \mathrm{ml}$. (Dooley JM et al. The use of antiepileptic drug levels in children: a survey of Canadian pediatric neurologists. Can I Neurol Sci Aug 1993;20:217-221). (Reprints: Dr JM Dooley, Neurology Division, The IWK Children's Hospital, University Ave, Halifax, Nova Scotia, Canada B3J 3G9).

COMMENT. The interpretation of AED levels may be misleading because trough level specimens are often impractical and therapeutic ranges used by laboratories are variable. The authors question the value of carbamazepine levels in children in particular, based on the findings in their survey. Their conclusions and concerns are confirmed by a report from the Poison Centers of Phiadelphia and Pittsburgh (Spiller HA, Krenzelok EP. Carbamazepine overdose: serum concentration less predictive in children. Clin Toxicol Sept 1993;31:459-460). A group of 29 children ages $1-12$ years were at risk of serious morbidity (seizures, coma, and mechanical ventilator) from CBZ overdose at lower serum concentrations $(27 \mathrm{mg} / \mathrm{L})$ than a group of 33 adult patients whose mean toxic CBZ levels for coma were $41-44 \mathrm{mg} / \mathrm{L}$. Serum levels were not accurate predictors of risk of toxic overdosage from carbamazepine in children. The following report shows that CBZ levels are more predictive of severe toxicity and morbidity in adults. 